\title{
Optimizing clopidogrel dose response: a new clinical algorithm comprising CYP2C19 pharmacogenetics and drug interactions
}

This article was published in the following Dove Press journal:

Therapeutics and Clinical Risk Management

23 September 2015

Number of times this article has been viewed

\author{
Yolande B Saab' \\ Rony Zeenny² \\ Wijdan H Ramadan² \\ 'School of Pharmacy, Pharmaceutical \\ Sciences Department, ${ }^{2}$ School of \\ Pharmacy, Pharmacy Practice \\ Department, Lebanese American \\ University, Byblos, Lebanon
}

Purpose: Response to clopidogrel varies widely with nonresponse rates ranging from $4 \%$ to $30 \%$. A reduced function of the gene variant of the CYP2C19 has been associated with lower drug metabolite levels, and hence diminished platelet inhibition. Drugs that alter CYP2C19 activity may also mimic genetic variants. The aim of the study is to investigate the cumulative effect of CYP2C19 gene polymorphisms and drug interactions that affects clopidogrel dosing, and apply it into a new clinical-pharmacogenetic algorithm that can be used by clinicians in optimizing clopidogrel-based treatment.

Method: Clopidogrel dose optimization was analyzed based on two main parameters that affect clopidogrel metabolite area under the curve: different CYP2C19 genotypes and concomitant drug intake. Clopidogrel adjusted dose was computed based on area under the curve ratios for different CYP2C19 genotypes when a drug interacting with CYP2C19 is added to clopidogrel treatment. A clinical-pharmacogenetic algorithm was developed based on whether clopidogrel shows 1) expected effect as per indication, 2) little or no effect, or 3) clinical features that patients experience and fit with clopidogrel adverse drug reactions.

Results: The study results show that all patients under clopidogrel treatment, whose genotypes are different from $* 1 * 1$, and concomitantly taking other drugs metabolized by CYP2C19 require clopidogrel dose adjustment. To get a therapeutic effect and avoid adverse drug reactions, therapeutic dose of $75 \mathrm{mg}$ clopidogrel, for example, should be lowered to $6 \mathrm{mg}$ or increased to $215 \mathrm{mg}$ in patients with different genotypes.

Conclusion: The implementation of clopidogrel new algorithm has the potential to maximize the benefit of clopidogrel pharmacological therapy. Clinicians would be able to personalize treatment to enhance efficacy and limit toxicity.

Keywords: pharmacogenetics, genotype, genetic testing, individualized therapy

\section{Introduction}

Clopidogrel is an oral antiplatelet agent and one of the commonly prescribed medications worldwide in the treatment of acute coronary syndrome and in patients undergoing percutaneous coronary intervention to prevent recurrent atherothrombotic events. ${ }^{1}$ Clopidogrel is also indicated in secondary prevention of stroke in high-risk patients, ${ }^{2}$ as an alternative for patients who are intolerant to aspirin, with atrial fibrillation and cannot take warfarin. ${ }^{3}$

Response to clopidogrel varies widely with nonresponse rates ranging from 4\% to $30 \%$ at 24 hours. ${ }^{4}$ Interindividual variability is due to the fact that clopidogrel is a pro-drug that requires intestinal absorption followed by enzyme biotransformation to yield its active metabolite, 2-oxoclopidogrel. This active thiol metabolite inhibits
Correspondence: Yolande B Saab School of Pharmacy, Pharmaceutical Sciences Department, Lebanese American University, PO Box 36 F-19, Byblos, Lebanon

Tel +96I 9547 254/262, Extension 2312 Fax +96I 9547256

Email ysaab@lau.edu.lb 
adenosine diphosphate (ADP)-induced platelet aggregation by blocking the platelet $\mathrm{P} 2 \mathrm{Y}_{12}$ receptor, resulting in approximately 50\% reduction in ADP-mediated platelet aggregation after therapeutically recommended doses. ${ }^{5}$

Suggested mechanisms for this variability have included under-dosing, intrinsic interindividual differences resulting from genetic polymorphisms, and drug interactions with CYP2C19 substrates and inhibitors..$^{6-8}$

A reduced function of the gene variant of the CYP2C19 that is located on chromosome 10 has been associated with lower clopidogrel metabolite levels, hence diminished platelet inhibition, and higher rates of adverse cardiovascular events, ${ }^{1,9-11}$ whereas an increased function of the gene variant of the CYP2C19 has been associated with higher clopidogrel metabolite levels, and consequently an increased risk of bleeding. ${ }^{7}$

Drug interactions may mimic genetic variants. Drugs can alter CYP2C19 activity, and those drugs are referred to as either inhibitors or inducers. Drugs that inhibit CYP2C19 activity are likely to decrease the plasma concentrations of the active metabolite of clopidogrel. On the other hand, some drugs induce (stimulate) CYP2C19, and they may increase the efficacy of CYP2C19 substrates like clopidogrel since more of the active metabolite is formed. Enzyme inducers tend to be "broad-spectrum", in that they often induce several CYP450 isozymes. Enzyme induction interactions may be hard to detect clinically, since reduced drug effect may be interpreted as simply a lack of patient drug response. ${ }^{8}$

Comprehensive information on the effects of CYP2C19 gene polymorphisms and drug-drug interactions on clopidogrel concentrations in patients concomitantly treated with clopidogrel and other drugs that affect CYP2C19 function is unavailable. The aim of the study is to 1) investigate the cumulative effect of CYP2C19 gene polymorphisms and drug interactions that affects the plasma levels of clopidogrel active metabolite dosing, and 2) apply dose adjustment in a new algorithm that can be used in optimizing treatment and stratifying patients for drug response. The algorithm aims at providing clinicians with a guide that helps in dosing patients who are concomitantly treated with clopidogrel and other drugs metabolized by CYP2C19.

\section{Methods}

The authors confirm there is no need for ethics approval as this study does not deal with any ethical issues. The cumulative effect of CYP2C19 gene polymorphisms and drug interactions that affects clopidogrel dosing was investigated based on the following rationale: clopidogrel is metabolized by CYP2C19; CYP2C19 enzyme activity is altered in subjects with mutated CYP2C19 alleles who may be poor metabolizers, intermediate metabolizers, or ultra-extensive metabolizers as compared to the extensive metabolizers. The activity of the enzyme is also affected by drug inducers and inhibitors. Thus, the cumulative effect influences the patient's response to clopidogrel. Drugs metabolized by CYP2C19 were identified and classified as enzyme inducers and inhibitors. CYP2C19 gene variants and their effects on the enzyme activity were also determined.

\section{Statistical analysis of data}

The cumulative effect was analyzed based on two main parameters that affect clopidogrel area under the curve (AUC): different CYP2C19 genotypes and polypharmacy. The general metrics used is the ratio of altered clopidogrel AUC, where the alteration may be caused by either gene polymorphism or drug interaction, to the reference AUC measured in patients with no mutation or no interaction. ${ }^{12}$ The study used a software ${ }^{13}$ to compute the AUC ratio for different CYP2C19 genotypes when a drug interacting with CYP2C19 is added to clopidogrel treatment. The adjusted dose was based on a current dose of $75 \mathrm{mg}$, taken as an example, and is calculated as follows: interacting drug $\mathrm{AUC}{ }^{\mathrm{XM}}$ with genotype (*)/AUC ${ }^{\mathrm{EM}} \times 75 \mathrm{mg}$, where AUC consists of the area under the clopidogrel active metabolite concentration in blood or plasma over the dosing interval at steady state; $\mathrm{AUC}^{\mathrm{EM}}$ is the AUC of clopidogrel given alone in "extensive metabolizers"; $\mathrm{AUC}^{\mathrm{XM}}$ is the AUC of the substrate given alone in patients with any other phenotype (ultra-extensive metabolizer to poor metabolizer) as defined by the genotype of the major CYP2C19 involved in the substrate metabolism; and $\mathrm{AUC}^{\mathrm{XM}^{*}}$ is the AUC of the substrate when given with an inhibitor or an inducer.

To obtain the adjusted dose for clopidogrel based on doses of 150,300 , and $600 \mathrm{mg}$, the adjusted dose of clopidogrel $75 \mathrm{mg}$ value shall be multiplied by 2,4 , and 8 , respectively.

For patients taking more than one CYP2C19 interacting drug along with clopidogrel, adjusted clopidogrel dose =

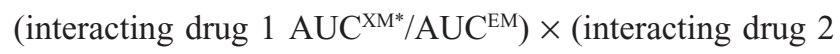
$\left.\mathrm{AUC}^{\mathrm{XM}^{*}} / \mathrm{AUC}^{\mathrm{EM}}\right) \times$ indicated clopidogrel dose.

Additionally, the study projected an algorithm as a clinical decision model for pharmacogenetic testing. The objective of the algorithm is to assess whether a pharmacogenetic testing is useful for a given patient under clopidogrel treatment. Three scenarios were anticipated: 1) the patient is well-controlled and shows expected clopidogrel effect as per indication, 2) the patient experiences little or no effect of clopidogrel, or 3 ) the patient presents with clinical features that fit with clopidogrel adverse drug reactions (ADRs). CYP2C19-drug interactions 
were mainly considered in the algorithm decisions. Patients' potential medications were explored for CYP2C19 inducers and/or inhibitors that interact with clopidogrel.

\section{Results Clopidogrel dose adjustment}

Clopidogrel dose adjustment was calculated based on a patient whose CYP2C19 genotype is known and a drug metabolized by CYP2C19 and interacting with clopidogrel is added to the patient's treatment. Table 1 includes a simulation for clopidogrel dose of $75 \mathrm{mg}$. Table 1 differentiates six genotypes classified into four groups: $* 17 * 17$ and $* 17 * 1$ identified as ultra-extensive metabolizers; $* 1 * 1$ extensive metabolizers; *2-3*17 and * $1 * 2-3$ intermediate metabolizers; and $* 2-3 * 2-3$ poor metabolizers.

The study results show that most patients under clopidogrel treatment whose genotypes are different from $* 1 * 1$ and concomitantly taking other drugs metabolized by inhibiting or inducing CYP2C19 most likely require clopidogrel dose adjustment. If concomitant drugs include but not limited to clarithromycin, fluconazole, fluoxetine, fluvoxamine, omeprazole, ticlopidine, and voriconazole, clopidogrel dose adjustment is required for all patients including $* 1 * 1$ genotypes. However, patients having the $* 17 * 17$ genotype and concomitantly taking a CYP2C19 inhibitor or those having the $* 1 * 2-3$ or $* 2-3 * 2-3$ and concomitantly taking a CYP2C19 inducer would probably not need dose adjustment. For example, if a patient has the $* 17 * 17$ genotype, clopidogrel $75 \mathrm{mg}$ as a standard therapeutic dose is required if clarithromycin $500-100 \mathrm{mg}$ /day has been added to the patient treatment. To get a therapeutic effect and avoid ADRs, clopidogrel dose should be lowered to $6 \mathrm{mg}$ and increased to $215 \mathrm{mg}$ in patients taking ritonavir and fluvoxamine, respectively. Commonly, $75 \mathrm{mg}$ is the indicated therapeutic dose for patients with $* 1 * 1$ genotype; the adjusted doses for patients with genotypes of $* 17 * 17$ and $* 17 * 1$ are 45 and $54 \mathrm{mg}$, respectively, whereas 86,137 , and $212 \mathrm{mg}$ are the adjusted doses for patients with $* 2-3 * 17, * 1 * 2-3$, and $* 2-3 * 2-3$ genotypes, respectively.

\section{Clinical-pharmacogenetic algorithm}

Currently, pharmacogenetic testing is performed in individual cases, and mostly retrospectively, for example, in patients who experience adverse effects or no therapeutic effect. Figure 1 depicts a proposed clinical decision algorithm for the use of pharmacogenetic testing. In brief, dosing patients on clopidogrel usually starts with the therapeutic doses as per indication. Three scenarios may apply.
Clinical situation one - supratherapeutic clopidogrel active metabolite

If the patient experiences clinical features that fit with clopidogrel ADRs, the clinician should first exclude other diagnoses and investigate the patient's polypharmacy. If ADRs are not due to any other problem and the patient treatment includes only clopidogrel, a pharmacogenetic testing is indicated.

However, if the patient drug intake includes CYP2C19 inducers, the latter should be discontinued and a switch to a drug not metabolized by CYP2C19 if available should be considered. If the above-mentioned clinical features persist, and/or no alternative to CYP2C19 inducer is available, a pharmacogenetic testing is indicated.

\section{Clinical situation two - subtherapeutic clopidogrel active metabolite}

If clopidogrel produces little or no therapeutic effect, the clinician should first exclude the possibility of using clopidogrel counterfeit and investigate the patient's polypharmacy. If the drug is genuine and the patient treatment includes only clopidogrel, a pharmacogenetic testing is indicated.

However, if the patient drug intake includes CYP2C19 inhibitors, the latter should be discontinued and a switch to a drug not metabolized by CYP2C19 if available should be considered. If the patient lab values do not show improvement, and/or no alternative to CYP2C19 inhibitor is available, a pharmacogenetic testing is indicated.

\section{Clinical situation three - therapeutic clopidogrel active metabolite}

If the patient is well-controlled and shows expected clopidogrel effect as per indication, clopidogrel should be continued as indicated without any change in dose.

\section{CYP2C19 pharmacogenetic test interpretation}

CYP2C19 genetic test results are provided with a genotype to phenotype interpretation. A normal metabolizer has two copies of the wild-type allele $(* 1 * 1)$ known as extensive metabolizer. ${ }^{11}$ When a variant allele replaces one or both wild-type alleles, this is interpreted as altered enzyme activity. Different variant alleles affecting CYP2C19 enzyme activity include: $* 17, * 2$, and $* 3$. If the genotype is $* 17 * 17$, and/or $* 1 * 17$, (known as ultra-metabolizer), ${ }^{11}$ a higher drug metabolite level is expected, and consequently a lower clopidogrel dose is indicated, whereas if the genotype has one allele *17 or *1 in combination with *2 or *3 (which are 
Table I Proposed dose adjustment of clopidogrel based on a patient whose CYP2CI9 genotype is known and a drug metabolized by CYP2CI 9 and interacting with clopidogrel is added

\begin{tabular}{|c|c|c|c|c|c|c|}
\hline \multirow[t]{2}{*}{ Interacting drug } & \multicolumn{6}{|c|}{ Different CYP2C19 genotypes } \\
\hline & $* 17 * 17$ & $*|*| 7$ & $* 1 * 1$ & $* 2-3 * 17$ & $* 1 * 2-3$ & $* 2-3 * 2-3$ \\
\hline Amiodarone $1,200 \mathrm{mg} / \mathrm{d}$ & $45(0.6)$ & $54(0.72)$ & $75(I)$ & $86(1.15)$ & $137(1.83)$ & $212(2.83)$ \\
\hline Azithromycin $250-500 \mathrm{mg} / \mathrm{d}$ & $45(0.6)$ & $54(0.72)$ & $75(I)$ & $86(1.15)$ & I37 (I.83) & $2 \mid 2(2.83)$ \\
\hline Benzbromarone $100 \mathrm{mg} / \mathrm{d}$ & $45(0.6)$ & $54(0.72)$ & $75(I)$ & $86(1.15)$ & $137(1.83)$ & $212(2.83)$ \\
\hline Boceprevir $800-2400 \mathrm{mg} / \mathrm{d}$ & $45(0.6)$ & $54(0.72)$ & $75(I)$ & $86(1.15)$ & $137(1.83)$ & $2 \mid 2(2.83)$ \\
\hline Bosentan $500-1,000 \mathrm{mg} / \mathrm{d}$ & $25(0.33)$ & $30(0.4)$ & $44(0.59)$ & $52(0.7)$ & $100(1.33)$ & $210(2.8)$ \\
\hline Bupropion 300 mg & $45(0.6)$ & $54(0.72)$ & $75(I)$ & $86(1.15)$ & $137(1.83)$ & $2 \mid 2(2.83)$ \\
\hline Carbamazepine $200-600 \mathrm{mg} / \mathrm{d}$ & $45(0.6)$ & $54(0.72)$ & $75(I)$ & $86(1.15)$ & $137(1.83)$ & $212(2.83)$ \\
\hline Cilcosporin $2.5-5 \mathrm{~g} / \mathrm{d}$ & $45(0.6)$ & $54(0.72)$ & $75(1)$ & $86(1.15)$ & $137(1.83)$ & $212(2.83)$ \\
\hline Cimetidine $800-1,200 \mathrm{mg} / \mathrm{d}$ & $45(0.6)$ & $54(0.72)$ & $75(I)$ & $86(1.15)$ & $137(1.83)$ & $212(2.83)$ \\
\hline Clarithromycin 500-1,000 mg/d & 75 (0.99) & $86(1.15)$ & I I I (I.48) & $123(1.64)$ & $167(2.23)$ & $213(2.84)$ \\
\hline Diltiazem $90-270$ mg/d & $45(0.6)$ & $54(0.72)$ & $75(I)$ & $86(1.15)$ & $137(1.83)$ & $212(2.83)$ \\
\hline Diphenhydramine $150 \mathrm{mg} / \mathrm{d}$ & $45(0.6)$ & $54(0.72)$ & $75(I)$ & $86(1.15)$ & $137(1.83)$ & $212(2.83)$ \\
\hline Dronedarone 800 mg/d & $45(0.6)$ & $54(0.72)$ & $75(I)$ & $86(1.15)$ & $137(1.83)$ & $2 \mid 2(2.83)$ \\
\hline Duloxetine $120 \mathrm{mg} / \mathrm{d}$ & $45(0.6)$ & $54(0.72)$ & $75(I)$ & $86(1.15)$ & $137(1.83)$ & $212(2.83)$ \\
\hline Efavirenz 600 mg/d & $45(0.6)$ & $54(0.72)$ & $75(I)$ & $86(1.15)$ & I37 (I.83) & $212(2.83)$ \\
\hline Erythromycin I,000-2,000 mg/d & $45(0.6)$ & $54(0.72)$ & $75(I)$ & $86(1.15)$ & $137(1.83)$ & $212(2.83)$ \\
\hline Fluconazole $100-400 \mathrm{mg} / \mathrm{d}$ & II 7 (I.56) & $130(1.73)$ & $152(2.03)$ & $161(2.15)$ & I9I (2.55) & $214(2.85)$ \\
\hline Fluoxetine $20-60 \mathrm{mg} / \mathrm{d}$ & $69(0.92)$ & 81 (I.08) & $105(1.4)$ & $117(1.56)$ & $164(2.18)$ & $213(2.84)$ \\
\hline Fluvoxamine $50-200 \mathrm{mg} / \mathrm{d}$ & $200(2.66)$ & $203(2.7)$ & $206(2.75)$ & $208(2.77)$ & $212(2.83)$ & $215(2.86)$ \\
\hline Gatifloxacin $400 \mathrm{mg} / \mathrm{d}$ & $45(0.6)$ & $54(0.72)$ & $75(I)$ & $86(1.15)$ & $137(1.83)$ & $212(2.83)$ \\
\hline Itraconazole $100-200$ mg/d & $45(0.6)$ & $54(0.72)$ & $75(I)$ & $86(1.15)$ & $137(1.83)$ & $212(2.83)$ \\
\hline Ketoconazole $200-400 \mathrm{mg} / \mathrm{d}$ & $45(0.6)$ & $54(0.72)$ & $75(I)$ & $86(1.15)$ & $137(1.83)$ & $212(2.83)$ \\
\hline Levomepromazine $10 \mathrm{mg} / \mathrm{d}$ & $45(0.6)$ & $54(0.72)$ & $75(I)$ & $86(1.15)$ & $137(1.83)$ & $212(2.83)$ \\
\hline Miconazole 125 mg/d & $45(0.6)$ & $54(0.72)$ & $75(I)$ & $86(1.15)$ & $137(1.83)$ & $212(2.83)$ \\
\hline Nefazodone 400 mg/d & $45(0.6)$ & $54(0.72)$ & $75(I)$ & $86(1.15)$ & $137(1.83)$ & $212(2.83)$ \\
\hline Noscapine $150 \mathrm{mg} / \mathrm{d}$ & $45(0.6)$ & $54(0.72)$ & $75(I)$ & $86(1.15)$ & $137(1.83)$ & $2 \mid 2(2.83)$ \\
\hline Omeprazole $40-80$ mg/d & $68(0.91)$ & $80(1.06)$ & $104(1.39)$ & $116(1.55)$ & $163(2.17)$ & $213(2.84)$ \\
\hline Pantoprazole $80 \mathrm{mg} / \mathrm{d}$ & $56(0.75)$ & $68(0.9)$ & $90(1.2)$ & $102(1.36)$ & I $52(2.02)$ & $213(2.84)$ \\
\hline Paroxetine $20 \mathrm{mg} / \mathrm{d}$ & $45(0.6)$ & $54(0.72)$ & $75(I)$ & $86(1.15)$ & $137(1.83)$ & $212(2.83)$ \\
\hline Phenytoin $300-400 \mathrm{mg} / \mathrm{d}$ & $25(0.33)$ & $30(0.4)$ & $44(0.59)$ & $53(0.7)$ & $100(1.33)$ & $210(2.8)$ \\
\hline Pioglitazone 45 mg/d & $45(0.6)$ & $54(0.72)$ & $75(I)$ & $86(1.15)$ & $137(1.83)$ & $212(2.83)$ \\
\hline Posacpnazole $200-600 \mathrm{mg} / \mathrm{d}$ & $45(0.6)$ & $54(0.72)$ & $75(I)$ & $86(1.15)$ & $137(1.83)$ & $212(2.83)$ \\
\hline Propafenone $675 \mathrm{mg} / \mathrm{d}$ & $45(0.6)$ & $54(0.72)$ & $75(I)$ & $86(1.15)$ & $137(1.83)$ & $212(2.83)$ \\
\hline Quinidine $50 \mathrm{mg}$ & $45(0.6)$ & $54(0.72)$ & $75(I)$ & $86(1.15)$ & $137(1.83)$ & $212(2.83)$ \\
\hline Ranitidine $300-600 \mathrm{mg} / \mathrm{d}$ & $45(0.6)$ & $54(0.72)$ & $75(I)$ & $86(1.15)$ & $137(1.83)$ & $212(2.83)$ \\
\hline Rifampicin 450-600 mg/d & I I (0.14) & $13(0.17)$ & $20(0.27)$ & $25(0.33)$ & $55(0.73)$ & $205(2.73)$ \\
\hline Ritonavir $800 \mathrm{mg} / \mathrm{d}>14 \mathrm{~d}$ & $6(0.08)$ & $7.5(0.1)$ & $12(0.16)$ & I5 (0.2) & $35(0.47)$ & $197(2.63)$ \\
\hline Roxithromycin 300 mg/d & $45(0.6)$ & $54(0.72)$ & $75(I)$ & $86(1.15)$ & $137(1.83)$ & $212(2.83)$ \\
\hline Saquinavir $3,600 \mathrm{mg} / \mathrm{d}$ & $45(0.6)$ & $54(0.72)$ & $75(I)$ & $86(1.15)$ & $137(1.83)$ & $212(2.83)$ \\
\hline Sertraline $150 \mathrm{mg} / \mathrm{d}$ & $45(0.6)$ & $54(0.72)$ & $75(I)$ & $86(1.15)$ & $137(1.83)$ & $212(2.83)$ \\
\hline St John Wart 600 mg/d & $29(0.38)$ & $35(0.47)$ & 5 I (0.68) & $86(1.15)$ & $110(1.46)$ & $210(2.8 I)$ \\
\hline Sulfamethizole $600 \mathrm{mg} / \mathrm{d}$ & $45(0.6)$ & $54(0.72)$ & $75(I)$ & $86(1.15)$ & $137(1.83)$ & $212(2.83)$ \\
\hline Sulfaphenazole $1,000 \mathrm{mg} / \mathrm{d}$ & $45(0.6)$ & $54(0.72)$ & $75(I)$ & $86(1.15)$ & I37 (I.83) & $212(2.83)$ \\
\hline Telaprevir $2.25 \mathrm{mg} / \mathrm{d}$ & $45(0.6)$ & $54(0.72)$ & $75(I)$ & $86(1.15)$ & I37 (I.83) & $212(2.83)$ \\
\hline Telithromycin 800 mg/d & $45(0.6)$ & $54(0.72)$ & $75(I)$ & $86(1.15)$ & $137(1.83)$ & $212(2.83)$ \\
\hline Terbinafine $250 \mathrm{mg} / \mathrm{d}$ & $45(0.6)$ & $54(0.72)$ & $75(I)$ & $86(1.15)$ & $137(1.83)$ & $212(2.83)$ \\
\hline Thioridazine $50 \mathrm{mg} / \mathrm{d}$ & $45(0.6)$ & $54(0.72)$ & $75(I)$ & $86(1.15)$ & $137(1.83)$ & $212(2.83)$ \\
\hline Ticagrelor $90-180 \mathrm{mg} / \mathrm{d}$ & $45(0.6)$ & $54(0.72)$ & $75(I)$ & $86(1.15)$ & $137(1.83)$ & $212(2.83)$ \\
\hline Ticlopidine 300 mg/d & $75(I)$ & $88(1.17)$ & II3 (I.5) & $86(1.15)$ & $168(2.24)$ & $214(2.84)$ \\
\hline Valproate $400-800 \mathrm{mg} / \mathrm{d}$ & $45(0.6)$ & $54(0.72)$ & $75(I)$ & $86(1.15)$ & $137(1.83)$ & $212(2.83)$ \\
\hline Verapamil $240-480 \mathrm{mg} / \mathrm{d}$ & $45(0.6)$ & $54(0.72)$ & $75(I)$ & $86(1.15)$ & $137(1.83)$ & $212(2.83)$ \\
\hline Voriconazole $400-800 \mathrm{mg} / \mathrm{d}$ & $100(\mathrm{I} .2 \mathrm{I})$ & $104(1.38)$ & I 28 (I.7I) & $140(1.86)$ & I 79 (2.38) & $214(2.85)$ \\
\hline
\end{tabular}

Notes: Clopidogrel adjusted dose in $\mathrm{mg}$ for clopidogrel dose of $75 \mathrm{mg}=$ (interacting drug AUC $\mathrm{MM}^{*} / \mathrm{AUC}^{\mathrm{EM}}$ ) $\times 75 \mathrm{mg}$. The values shown in bold refer to the dose, and the values in brackets refer to interacting AUC values. List of CYP2C19 inhibitors and inducers. AUC ratio calculation was adopted from Castellan et al. ${ }^{13}$ AUC consists of the area under the substrate concentration in blood or plasma over the dosing interval at steady state; AUCEM is the AUC of the substrate given alone in "extensive metabolizers"; $A U C^{X M}$ is the AUC of the substrate given alone in patients with any other phenotype (ultra-extensive metabolizer to poor metabolizer) as defined by the genotype of the major CYP2C19 involved in the substrate metabolism; $\mathrm{AUC}^{\mathrm{XM} \mathrm{M}^{*}}$ is the AUC of the substrate given with an inhibitor or an inducer. Data from Castellan et al. ${ }^{13}$ Abbreviations: AUC, area under the curve; d, day. 


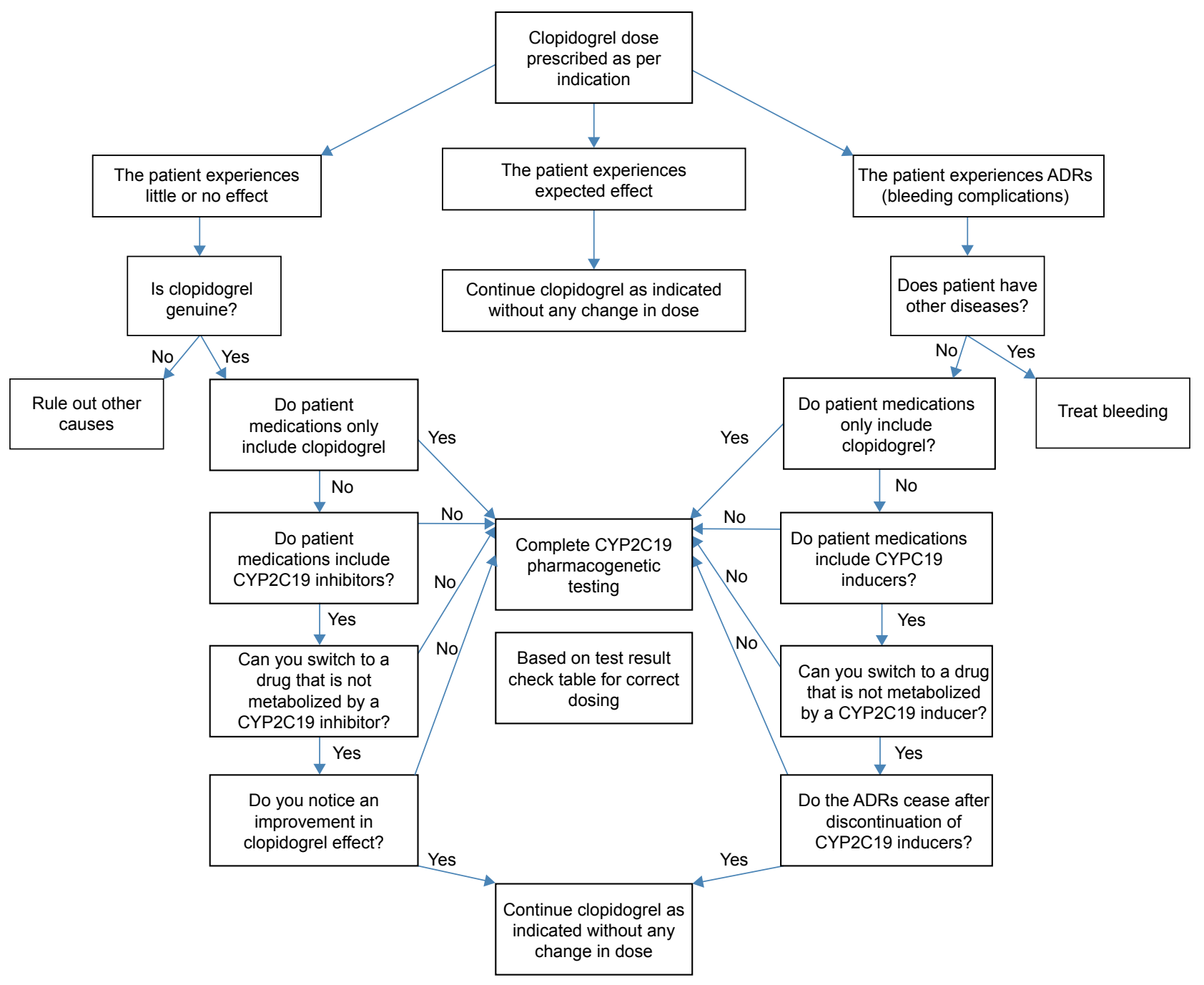

Figure I Clinical decision model algorithm for pharmacogenetic testing.

Abbreviation: ADRs, adverse reactions.

known as intermediate metabolizers) a lower drug metabolite level is expected, and consequently a higher clopidogrel dose is respectively indicated. A much higher dose is indicated if the patient genotype is homozygous $* 2$, or $* 3$, or includes $* 3$ and $* 2$ in combination (which are known as poor metabolizers). ${ }^{11}$

\section{Discussion}

Pharmacogenetics and drug interactions share a partnership in predicting patients' resistance or sensitivity to drugs related effects. Thus, understanding the synergistic/additive/ antagonistic/subtractive effects of gene polymorphisms and drug interactions provides better patient care. Clopidogrel remains the thienopyridine drug with the most approved indications for use. CYP2C19 genetic mutations and drug interaction-mediated inhibition/induction cause reduction/ enhancement in activity of the enzyme, providing mutually corroborating scientific evidence for the interpretation of clinical consequences. Genetic variation in CYP2C19 has shown to affect plasma levels/effect of active metabolite of clopidogrel and therefore clopidogrel dosing, and patients have revealed different CYP2C19 gene polymorphisms; approximately, $5 \%-30 \%$ of patients are ultra-metabolizers, $18 \%-45 \%$ are intermediate metabolizers, $2 \%-15 \%$ are poor metabolizers, as compared to $35 \%-50 \%$ of patients who are extensive metabolizers. ${ }^{14,15}$ Thus, dose adjustment would be required for almost more than $50 \%$ of patients.

To adjust clopidogrel dose and get the desired response in patients with loss of functional CYP2C19 allele, one option is to double the dose: the loading dose can be increased from 300 to $600 \mathrm{mg}$, and the maintenance dose from 75 to $150 \mathrm{mg}$. The benefit has been evident in several studies, ${ }^{16-24}$ whereas contradictory results have been shown in other studies. ${ }^{25,26}$ Another option is to switch from clopidogrel to a different 
P2Y12 antagonist. Several agents, such as prasugrel, ticagrelor, elinogrel, and cangrelor, have been approved for this purpose. Although the new drugs share a similar molecule or same mechanism of action to that of clopidogrel, and do not require CYP2C19 to biotransform into the active agent, patients have shown to be more prone to bleeding complications. ${ }^{27-29}$ The study provides an accurate dosing of clopidogrel as an alternative. Considering alternative dosing of clopidogrel, dose adjustment has to be accurately computed as shown in the study results; however, a major limitation is that clopidogrel is only available in $75 \mathrm{mg}$ and $300 \mathrm{mg}$ dosage strengths. Additionally, clopidogrel tablets are available as pills that cannot be split. Hence, if the patient requires a dose lower than 75 $\mathrm{mg}$, clinician should refer to a clopidogrel substitute.

When patients are extremely sensitive or resistant to clopidogrel effects at normal doses, the clinician should verify if the physical product is genuine if possible, exclude drug-drug interactions and then search for genetic variation in CYP2C19 metabolism as the underlying cause. The availability of such an alternative is integral to the process of integrating the use of the genetic biomarker into clinical decision-making, offering solutions to nonresponders or under-responders to therapy as well as to patients experiencing side effects from the drug.

\section{Conclusion}

In conclusion, the study integrates clopidogrel-drug interaction and pharmacogenetic studies in a clinical algorithm and provides an accurate dosing recommendation of clopidogrel. The implementation of such pharmacogenetic-drug interaction approach has the potential to maximize the benefit of clopidogrel pharmacological therapy and to refine the choice of pharmacological agent that may be administered along with clopidogrel in patients on polypharmacy. Clinicians would be able to personalize treatment to enhance efficacy and/or limit toxicity.

\section{Acknowledgment}

We would like to acknowledge the Lebanese American University for the financial support.

\section{Disclosure}

The authors report no conflicts of interest in this work.

\section{References}

1. Binazon O, Dubois-Gauche A, Nanau RM, Neuman MG. Efficacy and safety of platelet inhibitors. J Pharm Pharm Sci. 2013;16(1):1-39.

2. Gouya G, Arrich J, Wolzt M, et al. Antiplatelet treatment for prevention of cerebrovascular events in patients with vascular diseases: a systematic review and meta-analysis. Stroke. 2014;45(2):492-503.
3. Hankey GJ. Replacing aspirin and warfarin for secondary stroke prevention: is it worth the costs? Curr Opin Neurol. 2010;23(1):65-72.

4. Gurbel PA, Bliden KP, Hiatt BL, O'Connor CM. Clopidogrel for coronary stenting: response variability, drug resistance, and the effect of pretreatment platelet reactivity. Circulation. 2003;107:2908-2913.

5. Fareed J, Jeske W, Thethi I. Metabolic differences of current thienopyridine antiplatelet agents. Expert Opin Drug Metab Toxicol. 2013; 9(3):307-317.

6. U.S. Food and Drug Administration. FDA Drug safety communication: reduced effectiveness of Plavix (clopidogrel) in patients who are poor metabolizers of the drug. Available form: http://www.fda.gov/Drugs/ DrugSafety/PostmarketDrugSafetyInformationforPatientsandProvide rs/ucm203888.htm (March 12, 2010). Accessed January 31, 2015.

7. Mega JL, Close SL, Wiviott SD, et al. Cytochrome p-450 polymorphisms and response to clopidogrel. $N$ Engl J Med. 2009;360(4):354-362.

8. MaTKW, Lam YY, Tan VP, Yan BP. Variability in response to clopidogrel: how important are pharmacogenetics and drug interactions? $\mathrm{Br} J$ Clin Pharmacol. 2011;72(4):697-706.

9. Fuster V, Sweeny JM. Clopidogrel and the reduced-function CYP2C19 genetic variant: a limited piece of the overall therapeutic puzzle. JAMA. 2010;304:1839-1840.

10. Shuldiner AR, O'Connell JR, Bliden KP, et al. Association of cytochrome P450 2C19 genotype with the antiplatelet effect and clinical efficacy of clopidogrel therapy. JAMA. 2009;302(8):849-857.

11. Scott SA, Sangkuhl K, Stein CM, et al; Clinical Pharmacogenetics Implementation Consortium. Clinical Pharmacogenetics Implementation Consortium guidelines for CYP2C19 genotype and clopidogrel therapy: 2013 update. Clin Pharmacol Ther. 2013;94(3):317-323.

12. Goutelle S, Bourguignon L, Bleyzac N, Berry J, Clavel-Grabit F, Tod M. In vivo quantitative prediction of the effect of gene polymorphisms and drug interactions on drug exposure for CYP2C19 substrates. AAPS J. 2013;15(2):415-426.

13. Castellan C, Charpiat B, Gueyffier F, Kassaï B, Nony P, Genophar II working group. DDI-predictor. Available from: http://www.ddipredictor.org/. Accessed January 31, 2015.

14. Bertilsson L. Geographical/interracial differences in polymorphic drug oxidation. Current state of knowledge of cytochromes P450 (CYP) 2D6 and 2C19. Clin Pharmacokinet. 1995;29(3):192-209.

15. Desta Z, Zhao X, Shin JG, Flockhart DA. Clinical significance of the cytochrome P450 2C19 genetic polymorphism. Clin Pharmacokinet. 2002;41(12):913-958.

16. Simon T, Bhatt DL, Bergougnan L, et al. Genetic polymorphisms and the impact of a higher clopidogrel dose regimen on active metabolite exposure and antiplatelet response in healthy subjects. Clin Pharmacol Ther. 2011;90(2):287-295.

17. Gladding P, Webster M, Zeng I, et al. The antiplatelet effect of higher loading and maintenance dose regimens of clopidogrel: the PRINC (Plavix Response in Coronary Intervention) trial. JACC Cardiovasc Interv. 2008;1(6):612-619.

18. Gladding P, White H, Voss J, et al. Pharmacogenetic testing for clopidogrel using the rapid INFINITI analyzer: a dose-escalation study. JACC Cardiovasc Interv. 2009;2(11):1095-1101.

19. Barker CM, Murray SS, Teirstein PS, Kandzari DE, Topol EJ, Price MJ. Pilot study of the antiplatelet effect of increased clopidogrel maintenance dosing and its relationship to CYP2C19 genotype in patients with high ontreatment reactivity. JACC Cardiovasc Interv. 2010;3(10):1001-1007.

20. Bonello L, Armero S, Ait Mokhtar O, et al. Clopidogrel loading dose adjustment according to platelet reactivity monitoring in patients carrying the $2 \mathrm{C} 19 * 2$ loss of function polymorphism. $\mathrm{J} \mathrm{Am} \mathrm{Coll} \mathrm{Cardiol}$. 2010;56(20):1630-1636.

21. Alexopoulos D, Dimitropoulos G, Davlouros P, et al. Prasugrel overcomes high on-clopidogrel platelet reactivity post-stenting more effectively than high-dose (150-mg) clopidogrel: the importance of CYP2C19*2 genotyping. JACC Cardiovasc Interv. 2011;4(4):403-410.

22. Collet JP, Hulot JS, Anzaha G, et al; CLOVIS-2 Investigators. High doses of clopidogrel to overcome genetic resistance: the randomized crossover CLOVIS-2 (Clopidogrel and Response Variability Investigation Study 2). JACC Cardiovasc Interv. 2011;4(4):392-402. 
23. Hamilos M, Muller O, Ntalianis A, et al. Relationship between peripheral arterial reactive hyperemia and residual platelet reactivity after 600 mg clopidogrel. J Thromb Thrombolysis. 2011;32(1):64-71.

24. Mega JL, Hochholzer W, Frelinger AL 3rd, et al. Dosing clopidogrel based on CYP2C19 genotype and the effect on platelet reactivity in patients with stable cardiovascular disease. JAMA. 2011;306(20): 2221-2228.

25. Price MJ, Berger PB, Teirstein PS, et al; GRAVITAS Investigators. Standard- vs high-dose clopidogrel based on platelet function testing after percutaneous coronary intervention: the GRAVITAS randomized trial. JAMA. 2011;305(11):1097-1105.

26. Bonello L, Pansieri M, Mancini J, et al. High on-treatment platelet reactivity after prasugrel loading dose and cardiovascular events after percutaneous coronary intervention in acute coronary syndromes. $\mathrm{J} \mathrm{Am}$ Coll Cardiol. 2011;58(5):467-473.
27. Barthélémy O, Silvain J, Brieger D, et al. Bleeding complications in primary percutaneous coronary intervention of ST-elevation myocardial infarction in a radial center. Catheter Cardiovasc Interv. 2012;79(1): 104-112.

28. Caldeira D, Fernandes R, Costa J, et al. Branded versus generic clopidogrel in cardiovascular diseases: a systematic review. J Cardiovasc Pharmacol. 2013;61(4):277-282.

29. Wallentin L, Varenhorst C, James S, et al. Prasugrel achieves greater and faster P2Y12 receptor-mediated platelet inhibition than clopidogrel due to more efficient generation of its active metabolite in aspirin-treated patients with coronary artery disease. Eur Heart J. 2008;29:21-30.

\section{Publish your work in this journal}

Therapeutics and Clinical Risk Management is an international, peerreviewed journal of clinical therapeutics and risk management, focusing on concise rapid reporting of clinical studies in all therapeutic areas, outcomes, safety, and programs for the effective, safe, and sustained use of medicines. This journal is indexed on PubMed Central, CAS,
EMBase, Scopus and the Elsevier Bibliographic databases. The manuscript management system is completely online and includes a very quick and fair peer-review system, which is all easy to use. Visit http://www.dovepress.com/testimonials.php to read real quotes from published authors.

Submit your manuscript here: http://www.dovepress.com/therapeutics-and-clinical-risk-management-journal 